\section{Vol. 65, No. SS-8}

In the Surveillance Summary, "Prevalence of Amyotrophic Lateral Sclerosis - United States, 2012-2013," an error occurred on the cover. No continuing education examination is available for this report.

\section{Vol. 65, No. 28}

In the $M M W R$ report, "Projected Zika Virus Importation and Subsequent Ongoing Transmission after Travel to the 2016 Olympic and Paralympic Games - Country-Specific Assessment, July 2016," an error occurred throughout in reporting the number of countries participating in the 2016 Olympic and Paralympic Games without evidence of past Zika transmission: 18 countries (not 19 as stated) met this criterion. Thus, the fourth sentence of the fourth paragraph should have read, "For 14 of these countries, estimated aviation travel from Rio de Janeiro in August 2016 compared with total aviation travel from all countries with local Zika virus transmission in 2015 was $0.01 \%-3.04 \%$ (Table 2).” In addition, in Table 2, Angola should not have been listed, and the title should have read, "Participating countries currently not reporting Zika outbreaks $(\mathbf{n}=\mathbf{1 8})$ that met risk criteria for Zika virus importation and subsequent ongoing transmission attributed to travel to the Olympic and Paralympic Games, ranked by aviation travel volume* from Rio de Janeiro, Brazil — August 2016." 